\title{
Modernization of Governance System and Governance Capability of State-Owned Enterprises
}

\author{
Jingbo Xi*, Yu Liu \\ China electronics technology TAIJI GROUP Co., Ltd. Beijing 100083, China \\ *Corresponding author: Jingbo Xi, bopingrujing@126.com
}

\begin{abstract}
State-owned enterprises are important pillars of socialism with Chinese characteristics, and the modernization of their governance system and governance capacity is an important part of the modernization of the national governance system and governance capacity. Through case study and specific practice, this paper carries out an in-depth thinking and serious analysis on how to promote the modernization of the governance system and governance capacity of state-owned enterprises under the new situation and requirements. This paper puts forward three kinds of management and control mechanism to enhance core competence in addition to the specific implementation path by using digital governance means.
\end{abstract}

Keywords: State-owned enterprise governance system; Governance capability; High quality development; Basic management; Enterprise maturity

Publication date: August 2021; Online publication: August 30, 2021

\section{Introduction}

The Fourth Plenary Session of the $19^{\text {th }}$ Central Committee of the Communist Party of China made a major strategic plan to promote the modernization of the national governance system and governance capacity in addition to put forward higher requirements for the governance system and governance capacity of stateowned enterprises from the perspective of the national system and governance system. In recent years, state-owned enterprises have continued to consolidate their management foundation and strengthen their management innovation which led their management to achieve positive results. However, compared with world-class enterprises, there are still some problems, such as incomplete management system, imperfect system, and imperfect mechanism, which affect the quality and efficiency of enterprises to a certain extent. Especially in the face of complex external challenges and the impact of the global epidemic situation, stateowned enterprises must actively explore and improve the enterprise system and mechanism through selfreliance and intense training to be invincible in the increasingly complex and fierce competition environment.

The modernization of governance system and governance capability of state-owned enterprises refers to the fact that the current development concept and organizational design of state-owned enterprises are based on the social system with Chinese characteristics, conformed to the modern scientific theory and national policy with the use modern information technology for daily management, in addition to full of vigor and vitality along with a bright future ${ }^{[1]}$. In order to realize the modernization of state-owned enterprises' governance system and governance capability, there is a need to build a modern enterprise system, establish a modern governance concept, use modern governance means, and build an enterprise organization with efficient operation and scientific decision-making ${ }^{[2]}$. Combined with case study and practice, this paper puts forward the specific implementation path of state-owned enterprises to promote the modernization of governance system and governance capacity, which include the following aspects: the 
major decisions and arrangements of the Party Central Committee should be used as the strategic guidance for the reform and development of state-owned enterprises; a scientific management system for state-owned enterprises should be built; three types of management and control mechanisms should be built to enhance the core competence of state-owned enterprises, namely the closed-loop strategic management and control mechanism to enhance strategic driving capacity, a process management and control mechanism to enhance collaboration and efficiency, as well as a standardized two-level review mechanism to enhance the basic management; finally, through the means of digital governance to promote the concentration and interaction of information, the scientific decision-making of leaders is supported, the governance capability can be further improved, and high-quality development can be achieved.

\section{Using the major decisions and arrangements of the Party Central Committee as a strategic guidance}

Since the $18^{\text {th }}$ National Congress of the CPC Central Committee, the general secretary, Xi Jinping, has given innumerable speeches and instructions for the reform of state-owned enterprises in which the reform of these enterprises has taken a solid step. Since the $19^{\text {th }}$ National Congress of the CPC, strategic arrangements have been made for the structural adjustment of state-owned enterprises with the preservation and appreciation of state-owned assets, as well as the strengthening, optimization, and expansion of stateowned enterprises. In addition, new mobilization orders have also been issued for the reform of state-owned enterprises and central enterprises. The Fourth Plenary Session of the $19^{\text {th }}$ CPC Central Committee further made it clear to enhance the competitiveness, innovation, control, influence, and anti-risk ability of the state-owned economy, which put forward higher requirements for state-owned enterprises to improve their management ability and level. State-owned enterprises should have one principle that runs through all of them. There is a need to firmly implement the spirit of the general secretary's important speech and the instructions on state-owned enterprises reform, adhere to the "two consistent principles," use the banner of the Party as the guide, and transform theoretical study into concrete actions in order to promote reform and development to build reliable strength of the Party in governing and rejuvenating the country.

\section{Building a scientific management system ofs state-owned enterprises}

Modern enterprise management system is inseparable from governance with clear rights and responsibilities, sound and effective system management, as well as standardized and orderly basic management.

\subsection{Further improving the main body of governance}

Based on the Party Committee, the board of directors, and the managers, there is a need to establish and improve the decision-making implementation supervision mechanism with equal rights and responsibilities, coordinated operation and effective checks as well as balances, and give full play to the leadership role of the Party Committee, the decision-making role of the board of directors, as well as the executive role of the managers. The decision-making mechanism and efficiency should be improved, and the development of enterprises should be promoted through the main chain of the leadership decision execution. The Party Committee is the core of leadership in which they should "take the direction, manage the overall situation, and promote the implementation." On the other hand, the board of directors is the center of decision-making where they should "make strategies, make decisions, and prevent risks" whereas the management level is the operation command center where the responsibility is to "seek operation, grasp implementation, and strengthen management." 


\subsection{Further innovating the management system}

Based on the maturity model, there is a need to establish a quality process management system, confidentiality, and safety production. A strong wind control system should be built while audit and inspection should be conducted yearly to prevent and resolve major risks. A mission-oriented talent system should be built while stimulating talent creativity and building a first-class talent team. A financial management system represented by the sharing center mode can also be built to promote the integration of industry and finance in addition to a science and technology innovation management system of knowledge innovation, technology innovation, and platform innovation while anchoring the construction of core technology and products, focusing on the improvement of the overall efficiency of innovation platform, creating the source of science and technology innovation, and promoting science and technology selfreliance.

\subsection{Further strengthening the basic management}

There are many problems in state-owned enterprises, such as weak management system, weak modern concept, and weak basic management, which affect and restrict the efficient operation of these enterprises

${ }^{[3]}$. In order to improve the modern enterprise system, the governance capability of state-owned enterprises should be enhanced to achieve high-quality development by which the premise is in the standardization and professionalization of enterprises' basic management. State-owned enterprises should standardize post management, strengthen target management, optimize process management, improve distribution system, further consolidate management foundation, as well as promote continuous improvement and innovation. Post management uses the standardized assessment of post responsibilities within a department as an important starting point to ensure basic standardization. Target management uses two-level evaluation mechanism as the realization path to ensure the consistency of objectives. Process management uses key process optimization as a breakthrough to ensure the formation of task-based community. The distribution system focuses on salary management as well as medium and long-term incentives to ensure sustainable and high-quality development. Through the continuous improvement of the management, especially the basic management, the governance capability and level of state-owned enterprises can be improved.

\section{Building three kinds of management and control mechanism to enhance core competence of state- owned enterprises}

Based on the three-tier management system designed above, there is a need to build a closed-loop strategic management and control mechanism, a collaborative and efficient process management and control mechanism, as well as a standardized two-level review mechanism to ensure effective operation and further improve their governance capability.

\subsection{Building a closed-loop strategic management and control mechanism to enhance strategic driving capacity}

State owned enterprises should adhere to the concept of system, take strategic planning as the guide, strengthen forward thinking, overall planning, strategic layout, and overall promotion, as well as form a closed-loop strategy driving mechanism deciding four aspects - direction, task, control point, and effect from the strategy leading the programme, programme guiding the planning, planning deciding on the budget, and the budget determining the action. The strategy driving mechanism includes three stages: strategy formulation, strategy implementation, and strategy evaluation, covering from strategic planning research, formulation, implementation, evaluation, adjustment, to supervision. 


\subsubsection{Strategy formulation}

The core requirement of strategy formulation is "mission alignment, goal alignment, and train of thought alignment." The mission, vision, development goals, control points, key tasks, and implementation strategies of state-owned enterprises in a specific period are determined through four steps which include career insight, clear strategic intention, accurate innovation focus, and good business design.

\subsubsection{Strategy implementation}

Strategy implementation is the specific implementation of the annual task plan arrangement and evaluation which include the process of task deployment, plan arrangement, budget preparation, organization and implementation, supervision, evaluation, and adjustment so as to ensure the effective implementation of annual key tasks.

\subsubsection{Strategy evaluation}

Strategy evaluation is the key guarantee to ensure that the mission and responsibility of state-owned enterprises along with the development and reform are always advancing in the same direction with central decision-making and deployment, national strategic requirements, as well as major decisions. It is to evaluate the effect of strategy implementation through "relisting."

\subsection{Building a process control mechanism to enhance collaboration and efficiency}

In the face of the ever-changing market environment, state-owned enterprises should redesign and manage the process, constantly improve cost, quality, speed, and service in order to produce strategic advantages. State owned enterprises can conduct process and enterprise maturity model (PEMM) based assessment to identify the weak links of the enterprise process and form a process change roadmap. Through the analysis of American Productivity and Quality Center's (APQC's) Process Classification Framework, it further clarifies the focus of process change, and carry out specific process optimization according to the "five step" principle.

\subsubsection{Evaluation based on the process and enterprise maturity model (PEMM)}

PEMM, which is a process and enterprise maturity model that has been proposed by Michael Hammer, is suitable for any industry. It contains five factors to ensure the continuous high performance of the process: process dynamic factors (process design, process employees, process owners, infrastructure, indicators) and four enterprise capabilities (leadership, process management, culture, professional skills, governance). In PEMM, each principle has four maturity levels quantified by numerical value from "just started" to "best in class." This theoretical framework can help enterprises plan process change, track implementation progress, and identify obstacles to organizational change.

\subsubsection{Sorting out the existing process system and identify the key processes}

According to the APQC's Process Classification Framework, this paper combs the existing process system, forms the enterprise process management framework, systematically describes the business architecture, and examines the current business operation panorama. By combing the main process of the market chain, project or product chain, integrated supply chain, and other processes, it further clarifies the weak or missing links. 


\subsubsection{Promoting specific process optimization according to the "five step" principle}

First, the responsible department of the specific process is responsible for the overall design of the process and sub-process. Second, after the process optimization plan is approved, the new process will be tested in pilot departments where relevant trainings and system revisions will be carried out. The third is to establish a cross-departmental coordination mechanism to continuously improve the problem-solving skill among departments. Fourth, according to the online situation of the new process, the organization will evaluate the final results and effects of the process operation, whether the process objectives have been effectively achieved, as well as the specific situation of the process objectives. Fifth, according to the needs, the responsible department of the process will put forward suggestions on process informatization and assists in its construction.

\subsection{Building a two-level review mechanism to improve the standardization of basic management}

The basic management is the key to enterprises' long-term development. In order to consolidate the basic management, the basic management elements such as post responsibility, standard, process link, and time target should be taken as the starting point so as to improve the standardization level and institutionalization of management.

\subsubsection{Clarifying the division of responsibilities and form a goal-task linkage mechanism}

The responsibilities of the departments and employees are the basis of enterprise management. It is necessary to redefine and sort out the responsibilities of each department and employee so as to avoid overlapping responsibilities between departments and employees in reducing the blind area in the division of labor. On the basis of clear responsibilities and division of labor among departments and employees, annual objectives and key tasks of the enterprises should be further break down into departments and posts while having regular special meetings and conducting monthly assessments as well as supervisions. Through the two-level goal-task linkage mechanism, the goal is broken down layer by layer, and the responsibility is implemented step by step so as to further form a joint force and realize the task closedloop management.

\subsubsection{Defining the standards and specifications while forming a two-level (department and enterprise) review mechanism}

Department level review will focus on employee performance evaluation and performance application. On the one hand, there will be comments on the completion of key tasks of the month and performance feedback will be given after trend analysis. On the other hand, staff problems and suggestions will be collected and solved in time to close the loop so as to promote the overall performance of employees from two aspects: evaluation and assistance. The enterprise level review focuses on problem orientation and goal orientation in addition to comprehensively evaluate the completion of key tasks of each department in the current month, internal management of each department, rationalization suggestions, and service satisfaction so as to clarify the existing gaps and build on the goal. In particular, rationalization suggestions should be taken as the focus of the monthly review. Through continuous collection of rationalization suggestions, suggestions on responsibilities, processes, systems, informatization, and other aspects, the closed-loop management should be proposed, continuous improvement should be made, collective wisdom should be given full play, shortcomings of enterprises should be brought up, prominent problems should be solved, and management ability should be improved. 


\subsubsection{Having clear objectives and problem orientation while forming a closed-loop management mechanism of "assessment evaluation feedback"}

Through the design of a comprehensive monthly evaluation system and clear evaluation criteria, a normalized closed-loop management mechanism of "management evaluation meeting held by the department, assessment report filled by the department, leader evaluation and feedback from the main responsible department" can be formed. Through this closed-loop management mechanism, enterprises can achieve positive interaction and effectively improve their competitiveness.

\section{Using means of digital and information management}

The development of information technology is able to increase the speed and accuracy of state-owned enterprises' daily management so as to support decision-making more scientifically and improve the quality as well as the efficiency of management. Based on the existing information infrastructure, state-owned enterprises should build an efficient and standardized workflow system with the help of management system and business system, realize online, visualization, and instantaneity, as well as promote the standardization, process, and transparency of governance system.

In target assessment, for example, through goal setting and an evaluation management system that allows the enterprise to undergo "goal setting - target decomposition - data analysis - monthly assessment by supervisor - annual appraisal target adjustment -," the whole life cycle of performance management forms a complete control loop, which effectively enhance the level of enterprise management control and security business goals (Figure 1).

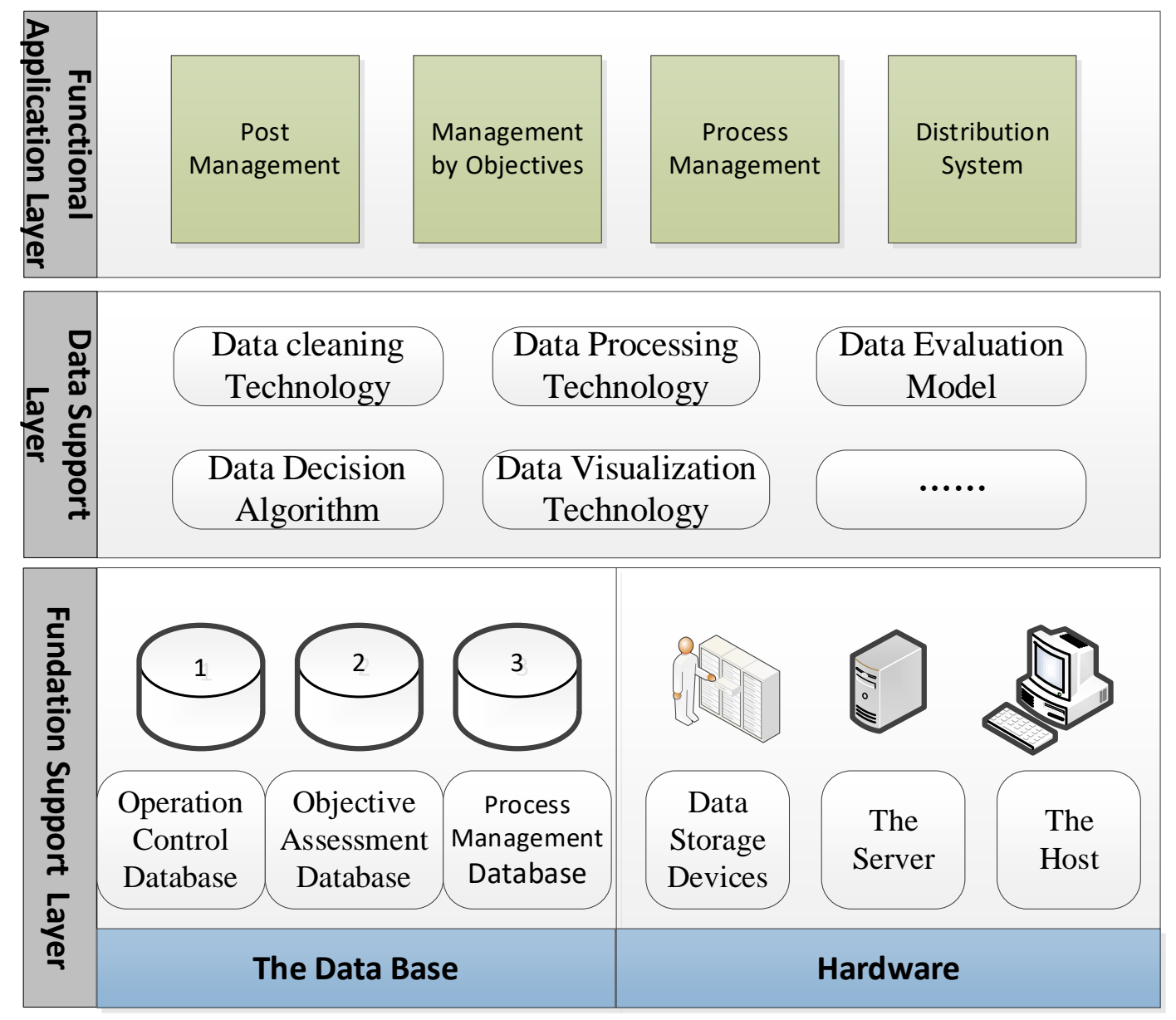

Figure 1. Overall framework of the system 


\section{Inspirations}

First, state-owned enterprises should build a scientific operation and management system, promote the internal connection and horizontal cooperation, improve their governance capability, and achieve highquality development.

Second, state-owned enterprises should also lay a solid foundation for management (post management, target management, process management, etc.) and improve the standardization level of management to build a solid foundation for development.

Third, state-owned enterprises should promote the reform of the system and mechanism through digital transformation. This is the only way for state-owned enterprises to deepen the reform and build a new development pattern. Actively promoting digital transformation is not only a response to the call of the government, but it also an important way to maintain core competitiveness.

\section{Disclosure statement}

The authors declare that there is no conflict of interest.

\section{References}

[1] Chen J, Cao X, 2019, Construction of an Evaluation System for the Modernization of State-Owned Enterprise Governance System and Governance Capability. China Development Observation, (24).

[2] Huang D, Yu D, 2021, Modernization of Governance System and Governance Capability of StateOwned Enterprises. Zhejiang Economy, (04).

[3] Qian Y, Bi C, 2021, Promoting the Construction of International First-Class Enterprises by Improving the Management of State-Owned Enterprises. Economic Reference, (007).

[4] Hammer M, Hushman L, 2020, End to End Process Creates Real Value for Customers, China Machine Press, Beijing, 126.

[5] Wang Y, Ge X, 2016, Process Management (5th Edition), Peking University Press, Beijing.

[6] Du W, Tao H, 2020, Development Trend and Management Mechanism of State-Owned Enterprise Reform. Modern Commerce, (16).

[7] 2021, How does an elephant turn around? Research Report on the digital transformation of central enterprises in 2021. Enterprise Management, (06): 50-3.

[8] Zhang B, 2021, The Way to Realize the Modernization of the Governance of State-Owned Assets and Enterprises. Social Governance, 2021 (02): 15-9.

[9] Ren R, 2015, On Promoting the Modernization of State-Owned Enterprise Governance System and Governance Capacity. Mall Modernization, (23): 102-3. 